\title{
Biomarkers of Oxidative Stress Associated with the Risk of Potentially Malignant Oral Disorders
}

\author{
THOMAS SENGHORE ${ }^{1,2}$, YU-FENG LI ${ }^{3}$, FUNG-CHANG SUNG ${ }^{4}$, MING-HSUI TSAI ${ }^{5}$, \\ CHUN-HUNG HUA ${ }^{5}$, CHIU-SHONG LIU ${ }^{6}$, RU-JIUN HUANG ${ }^{1}$ and CHIH-CHING YEH $^{1,7}$ \\ ${ }^{1}$ School of Public Health, College of Public Health, Taipei Medical University, Taipei, Taiwan, R.O.C; \\ ${ }^{2}$ Department of Nursing, School of Medicine and Allied Health Sciences, \\ University of The Gambia, Banjul, Gambia; \\ ${ }^{3}$ Graduate Institute of Biostatistics, Departments of ${ }^{4}$ Health Services Administration, \\ ${ }^{5}$ Otolaryngology, and ${ }^{6}$ Family Medicine, China Medical University Hospital, Taichung, Taiwan, R.O.C.; \\ ${ }^{7}$ Public Health, College of Public Health, China Medical University, Taichung, Taiwan, R.O.C.
}

\begin{abstract}
Aim: To investigate the effect of oxidative stress biomarkers on the risk of potentially malignant oral disorders (PMODs). Materials and Methods: A total of 208 male adults with PMODs and an equal number of same-age control patients were enrolled. Plasma biomarkers of oxidative stress, measured with 8-hydroxy-2'-deoxyguanosine (8-OHdG) and 8-isoprostane (8-ISO), were determined using enzyme-linked immunosorbent assay (ELISA) kits. PMODs were diagnosed in accordance with the World Health Organization (WHO) guidelines. Results: A significant association between a high level of 8-ISO and an increased risk of PMODs was identified [odds ratio $(O R)=1.71,95 \%$ confidence interval $(C I)=1.12-2.63 ; p=0.013]$. This positive association was stronger among patients with $P M O D$ subtype of leukoplakia (OR=1.94, 95\% Cl=1.24-3.06; $p=0.004)$. However, no significant association was observed between plasma 8-OHdG levels and overall risk of PMODs or subtypes. Conclusion: Increased plasma 8-ISO levels may indicate the prominence of lipid peroxidation in the development of PMODs, particularly leukoplakia.
\end{abstract}

Potentially malignant oral disorders (PMODs) pose a pressing public health challenge because of their high rate of transformation into oral malignancies. In Taiwan, oral cancer (OC) is a leading cause of mortality, especially among men

Correspondences to: Professor Chih-Ching Yeh, Ph.D., MSPH, School of Public Health, College of Public Health, Taipei Medical University, $250 \mathrm{Wu}-\mathrm{H} \operatorname{sing}$ Street, Taipei 11031, Taiwan. Tel: +886 $27361661 \mathrm{ext}$ 6534, Fax: +886 227384831, e-mail: ccyeh@tmu.edu.tw

Key Words: Potentially malignant oral disorders, leukoplakia, oxidative stress, biomarkers. aged 24 to 44 years (1), indicating the necessity of early intervention.

Tumor development is a complex process that is mediated by numerous endogenous and exogenous factors (2). Prominent among these is the induction of reactive oxygen species (ROS). At normal physiological concentrations, ROS act as signal molecules mediating cell growth, migration, and differentiation. High concentrations, however, induce cell death, apoptosis, and senescence (3), particularly when the antioxidant defense is overwhelmed. ROS can oxidize lipids and proteins and interact directly with DNA, thereby triggering oxidative stress $(4,5)$, which can lead to manifestation of 8-hydroxy-2'-deoxyguanosine (8-OHdG) and 8 -isoprostane (8-ISO) as biomarkers of oxidative damage (4, $6)$. Oxidative stress has been implicated in the pathogenesis of various pathologies, including oral tumors $(7,8)$.

The cytochrome P-450 (CYP-450) and glutathione S-transferase (GST) families of enzymes, which are involved in the metabolism and detoxification of toxic endogenous and environmental agents (9), play key roles in combating toxicity and ROS generation through their metabolites (10). We demonstrated in a previous study that genetic polymorphism in GSTM1 and CYP1A1*2C may increase susceptibility to PMODs, especially among smokers (11). Moreover, accumulated evidence has helped identify certain lifestyle factors, such as cigarette smoking, alcohol consumption, and betel-nut chewing, as risks for PMODs (12). Whether oxidative stress is associated with the risk of PMODs and whether such an association may be modified by genetic, environmental or lifestyle factors remains unclear.

Thus, the aim of this study was to investigate the association between oxidative stress biomarkers, measured based on 8-OHdG and 8-ISO levels, and the risk of PMODs. Additionally, we investigated how lifestyle factors and 
Table I. Comparison of characteristics of healthy controls and patients with potentially malignant oral disorders.

\begin{tabular}{|c|c|c|c|}
\hline Variable ${ }^{a}$ & Controls $(\mathrm{N}=208)$ & Cases $(\mathrm{N}=208)$ & $p$-Value ${ }^{c}$ \\
\hline Mean \pm SD age, years & $38.45 \pm 9.3$ & $38.78 \pm 9.1$ & 0.719 \\
\hline Mean $\mathrm{BMI} \pm \mathrm{SD}, \mathrm{kg} / \mathrm{m}^{2}$ & $24.07 \pm 3.1$ & $24.76 \pm 3.8$ & 0.038 \\
\hline BMI & & & 0.019 \\
\hline Normal weight $\left(<24 \mathrm{~kg} / \mathrm{m}^{2}\right)$ & $116(55.77 \%)$ & $92(44.23 \%)$ & \\
\hline Overweight $\left(\geq 24 \mathrm{~kg} / \mathrm{m}^{2}\right)$ & $92(44.23 \%)$ & $116(55.77 \%)$ & \\
\hline Educational level, n (\%) & & & 0.076 \\
\hline Below elementary school & $35(16.83 \%)$ & $40(19.51 \%)$ & \\
\hline Junior high school & $90(43.27 \%)$ & $105(51.22 \%)$ & \\
\hline Above senior high school & $83(39.90 \%)$ & $60(29.27 \%)$ & \\
\hline Cigarette smoking, n (\%) & & & 0.141 \\
\hline Nonsmoker & $11(5.29 \%)$ & $5(2.40 \%)$ & \\
\hline Current smoker & $180(86.54 \%)$ & $192(92.31 \%)$ & \\
\hline Ex-smoker & $17(8.17 \%)$ & $11(5.29 \%)$ & \\
\hline \multicolumn{4}{|l|}{ Cigarette pack-years, $\mathrm{n}(\%)^{\mathrm{b}}$} \\
\hline$<13$ & $108(51.92 \%)$ & $96(46.15 \%)$ & 0.239 \\
\hline$\geq 13$ & $100(48.08 \%)$ & $112(53.85 \%)$ & \\
\hline Alcohol consumption, $\mathrm{n}(\%)$ & & & 0.871 \\
\hline Never & $73(35.10 \%)$ & $68(32.69 \%)$ & \\
\hline Current drinker & $75(36.06 \%)$ & $77(37.02 \%)$ & \\
\hline Ex-drinker & $60(28.85 \%)$ & $63(30.29 \%)$ & \\
\hline Betel-nut chewing, $\mathrm{n}(\%)$ & & & 0.019 \\
\hline Never & $76(36.54 \%)$ & $50(24.04 \%)$ & \\
\hline Current chewer & $48(23.08 \%)$ & $62(29.81 \%)$ & \\
\hline Ex-chewer & $84(40.38 \%)$ & $96(46.15 \%)$ & \\
\hline Family history of cancer, $\mathrm{n}(\%)$ & & & 0.817 \\
\hline No & $160(76.92 \%)$ & $158(75.96 \%)$ & \\
\hline Yes & $48(23.08 \%)$ & $50(24.04 \%)$ & \\
\hline Median 8-OHdG (range), ng/mg & $51.59(228)$ & $43.33(209)$ & 0.053 \\
\hline Median 8-ISO (range), $\mathrm{pg} / \mathrm{ml}$ & $666.21(3565)$ & $790.26(2242)$ & 0.009 \\
\hline
\end{tabular}

$\mathrm{SD}$, Standard deviation; BMI, body-mass index; 8-OHdG, 8-hydroxy-2'-deoxyguanosine; 8-ISO, 8-isoprostane. aNumbers may not equal the total number because of missing data. ${ }^{b}$ Divided according to median cigarette pack-years among control patients. 'Student's $t$-test, Pearson's Chi-squared test, or Kruskal-Wallis test.

genetic polymorphisms affected the association between oxidative stress biomarkers and PMOD risk.

\section{Materials and Methods}

Participants. This case-control study included 208 male patients with PMODs and an equal number of control patients without oral lesions. A detailed description of participant characteristics has already been published (11). In brief, participants were recruited from a male penitentiary in Taiwan. A complete oral examination was conducted on all participants by two experienced otolaryngologists in accordance with World Health Organization guidelines (13). Patients with PMOD were those diagnosed with submucous fibrosis or leukoplakia, and controls of the same ages were randomly selected from individuals with healthy oral-screening results.

All eligible subjects completed a self-administered questionnaire covering information on sociodemographics, personal and family medical history, and lifestyle habits such as cigarette smoking, betel-nut chewing, and alcohol consumption. Based on their habits, participants were categorized as nonsmokers, current smokers (had been smoking for more than 1 year), or former smokers (had not smoked for at least the previous 6 months). Total cigarette consumption was computed in pack-years (PY), as the number of packs of cigarettes smoked daily multiplied by the duration of time (years) spent smoking. Body-mass index (BMI) was calculated from weight and height measurements as (weight/height ${ }^{2} ; \mathrm{kg} / \mathrm{m}^{2}$ ). The Ethics Review Committee of China Medical University and Hospital approved this study (IRB No: DMR96-IRB-085). All participants provided written, informed consent following a detailed explanation of the study objectives.

DNA isolation and genotyping. The methods for DNA isolation and genotyping were reported previously (11). In summary, $10 \mathrm{ml}$ of venous blood was collected from all participants for genomic extraction. From buffy-coated cells, genomic DNA for genotyping was isolated. Genotyping of GSTM1, GSTT1, GSTP1, and CYP1A1*2C was performed through polymerase chain reaction/restriction fragment length polymorphism. A $10 \%$ random sample was retested and showed $100 \%$ concordance for all polymorphisms. All laboratory personnel were blinded to disease status of participants.

Measurements of plasma 8-OHdG and 8-ISO. Measurements of 8OHdG and 8-ISO in plasma samples were carried out using 
Table II. Associations between biomarkers of oxidative stress and risk of potentially malignant oral disorders.

\begin{tabular}{|c|c|c|c|c|c|c|c|c|c|c|}
\hline \multirow[b]{2}{*}{ Biomarker ${ }^{\mathrm{a}}$} & \multirow{2}{*}{$\begin{array}{c}\text { Controls } \\
\mathrm{N}=208\end{array}$} & \multicolumn{3}{|c|}{ All cases } & \multicolumn{3}{|c|}{ Leukoplakia } & \multicolumn{3}{|c|}{ Submucous fibrosis } \\
\hline & & $\mathrm{N}=208$ & OR $(95 \% \mathrm{CI})^{\mathrm{b}}$ & $p$-Value & $\mathrm{N}=168$ & OR $(95 \% \mathrm{CI})^{\mathrm{b}}$ & $p$-Value & $\mathrm{N}=40$ & OR $(95 \% \mathrm{CI})^{\mathrm{b}}$ & $p$-Value \\
\hline \multicolumn{11}{|c|}{ 8-OHdG, ng/mg } \\
\hline$<51.59$ & 104 & 119 & 1.00 & & 87 & 1.00 & & 32 & 1.00 & \\
\hline$\geq 51.59$ & 104 & 89 & $0.71(0.47-1.09)$ & 0.115 & 81 & $0.93(0.59-1.45)$ & 0.744 & 8 & $0.22(0.31-1.03)$ & 0.063 \\
\hline \multicolumn{11}{|l|}{ 8-ISO, pg/ml } \\
\hline$<666.21$ & 104 & 79 & 1.00 & & 59 & 1.00 & & 20 & 1.00 & \\
\hline$\geq 666.21$ & 104 & 129 & $1.71(1.12-2.63)$ & 0.013 & 109 & $1.94(1.24-3.06)$ & 0.004 & 20 & $1.24(0.58-2.67)$ & 0.587 \\
\hline
\end{tabular}

8-ISO, 8-Isoprostane; BMI, body-mass index; 8-OHdG, 8-hydroxy-2'-deoxyguanosine; OR, odds ratio; CI, confidence interval. aMedian values based on controls. ${ }^{b}$ Adjusted for education, BMI, cigarette smoking (pack-years), alcohol consumption, and betel-nut chewing.

enzyme-linked immunosorbent assay kits (Cayman Chemical Company, Ann Arbor, MI, USA) by following the kit protocol. The intra- and inter-assay variability coefficients were $4.7 \%-11.6 \%$ and $4.5 \%-10.7 \%$, respectively, for $8-\mathrm{OHdG}$, and $6.4 \%-12.6 \%$ and $10.5 \%-24.3 \%$, respectively, for 8 -ISO.

Statistical analysis. Data analysis was performed using the SAS Statistical Package (Vers. 9.4 for Windows; SAS Institute, Cary, NC, USA). Statistical differences between cases and controls were assessed using the Student's $t$-test, Pearson's chi-squared test, or the KruskalWallis test, where appropriate. Logistic regression models were used to calculate odds ratios (ORs) and 95\% confidence intervals (CIs) to assess the association between oxidative stress biomarkers and risk of PMODs. Adjusted ORs were calculated using multivariate logistic regression models with adjustments for education, BMI, cigarette smoking (PY), alcohol consumption, and betel-nut chewing. Further analysis was conducted to examine the effects of lifestyle factorbiomarker and gene-biomarker interactions on the risk of PMODs. The levels of 8-OHdG and 8-ISO were dichotomized into binary variables according to median values for the controls. The joint effects of lifestyle factors (cigarette smoking, alcohol consumption, and betelnut chewing), and genetic polymorphisms (GSTM1, GSTT1, GSTP1, and $C Y P 1 A 1 * 2 C)$ with biomarkers were also estimated using multivariate regression models with adjustments for covariates. Due to the high proportion of smokers in our sample, the median smoking time among controls (13 PY) was used to examine the interaction between biomarkers and smoking habit. Statistical significance was two-sided and set at $p<0.05$.

\section{Results}

Table I compares characteristics between cases and controls. The case group had higher mean BMI $(p=0.038)$, a higher proportion of overweight subjects $(p=0.019)$, a higher proportion of current and former betel-nut chewers $(p=0.019)$, a lower median $8-\mathrm{OHdG}$ level $(p=0.053)$, and a higher median 8 -ISO level $(p=0.009)$ than did the control group.

No significant association was observed between 8-OHdG and overall risk of PMODs or leukoplakia in the multivariate logistic regression models. However, high levels of 8-OHdG were marginally significantly associated with lower risk of submucous fibrosis $(p=0.063)$. Additionally, 8-ISO was significantly associated with an increased risk of PMODs $(p=0.013)$ and leukoplakia $(p=0.004)$ but not with an increased risk of submucous fibrosis $(p=0.587)$ (Table II). Therefore, we further examined the joint effects of 8-ISO and lifestyle or genetic factors on the risk of PMODs.

Table III lists the effects of 8-ISO on the risk of PMODs and leukoplakia, as stratified according to lifestyle factors. No statistically significant interaction between 8-ISO and lifestyle factors was observed; however, 8-ISO elevation conferred an approximately two-fold or more increased risk of PMODs and leukoplakia in participants with $\leq 13 \mathrm{PY}$ of smoking ( $p=0.018$ and $p=0.002$, respectively) and in participants who ever consumed alcohol ( $p=0.046$ and $p=0.014$, respectively). Moreover, 8-ISO elevation more than doubled the risk of leukoplakia alone in participants who had never been betelnut chewers $(p=0.027)$ and significantly increased risk in those who had been betel-nut chewers $(p=0.046)$.

No significant interaction was observed between genetic polymorphisms and the oxidative stress biomarker on risks for PMODs or leukoplakia. After stratifying according to genotype, participants with GSTM1-null $(p=0.038)$ or $C Y P 1 A 1 * 2 C$ AA $(p=0.034)$ genotypes and high 8-ISO level exhibited a significantly increased risk of leukoplakia. Participants with GSTT1-null ( $p=0.005$ and $p=0.002)$ or GSTP1 AA $(p=0.027$ and $p=0.015$ ) genotypes and high 8-ISO level exhibited increased risk of both PMOD and leukoplakia (Table IV).

\section{Discussion}

PMODs carry a significant risk for malignant transformation (14). Among them, OC is highly prevalent in Taiwan (15). Evidence has linked oxidative DNA damage and lipid peroxidation to such malignancies, including OC $(7,16,17)$. In this study, we demonstrated that a high 8-ISO level was significantly associated with an increased risk of PMODs, particularly leukoplakia. We also revealed that both genetics 
Table III. Association between 8-isoprostane (8-ISO) level and the risk of potentially malignant oral disorders, stratified according to lifestyle factors.

\begin{tabular}{|c|c|c|c|c|c|c|c|c|}
\hline \multirow[b]{2}{*}{ Factor } & \multirow[b]{2}{*}{ 8-ISO, pg/ml } & \multirow{2}{*}{$\begin{array}{c}\text { Controls } \\
\mathrm{N}=208\end{array}$} & \multicolumn{3}{|c|}{ All cases } & \multicolumn{3}{|c|}{ Leukoplakia } \\
\hline & & & $\mathrm{N}=208$ & OR $(95 \% \mathrm{CI})$ & $p$-Value & $\mathrm{N}=168$ & OR $(95 \% \mathrm{CI})$ & $p$-Value \\
\hline \multicolumn{9}{|c|}{$\begin{array}{l}\text { Cigarette smoking } \\
\text { (pack-years) }\end{array}$} \\
\hline \multirow[t]{2}{*}{$\leq 13$} & $<666.21$ & 56 & 34 & 1.00 & & 21 & 1.00 & \\
\hline & $\geq 666.21$ & 52 & 62 & $2.07(1.13-3.79)^{\mathrm{a}}$ & 0.018 & 53 & $2.83(1.45-5.53)^{\mathrm{a}}$ & 0.002 \\
\hline \multirow[t]{2}{*}{$>13$} & $<666.21$ & 48 & 45 & 1.00 & & 38 & 1.00 & \\
\hline & $\begin{array}{c}\geq 666.21 \\
p \text { for interaction }\end{array}$ & 52 & 67 & $1.47(0.77-2.81)^{\mathrm{a}}$ & $\begin{array}{l}0.339 \\
0.408\end{array}$ & 56 & $1.43(0.74-2.78)^{\mathrm{a}}$ & $\begin{array}{l}0.288 \\
0.099\end{array}$ \\
\hline \multicolumn{9}{|c|}{ Alcohol consumption } \\
\hline \multirow[t]{2}{*}{ Never } & $<666.21$ & 35 & 24 & 1.00 & & 21 & 1.00 & \\
\hline & $\geq 666.21$ & 38 & 44 & $2.05(0.89-4.70)^{\mathrm{b}}$ & 0.091 & 37 & $1.90(0.81-4.47)^{\mathrm{b}}$ & 0.141 \\
\hline \multirow[t]{2}{*}{ Ever } & $<666.21$ & 69 & 55 & 1.00 & & 38 & 1.00 & \\
\hline & $\begin{array}{c}\geq 666.21 \\
p \text { for interaction }\end{array}$ & 66 & 85 & $1.70(1.01-2.87)^{\mathrm{b}}$ & $\begin{array}{l}0.046 \\
0.640\end{array}$ & 72 & $2.03(1.15-3.55)^{\mathrm{b}}$ & $\begin{array}{l}0.014 \\
0.937\end{array}$ \\
\hline \multicolumn{9}{|c|}{ Betel-nut chewing } \\
\hline \multirow[t]{2}{*}{ Never } & $<666.21$ & 38 & 20 & 1.00 & & 15 & 1.00 & \\
\hline & $\geq 666.21$ & 38 & 30 & $2.12(0.95-4.73)^{\mathrm{c}}$ & 0.067 & 28 & $2.68(1.12-6.43)^{\mathrm{c}}$ & 0.027 \\
\hline \multirow[t]{3}{*}{ Ever } & $<666.21$ & 66 & 59 & 1.00 & & 44 & 1.00 & \\
\hline & $\geq 666.21$ & 66 & 99 & $1.60(0.95-2.69)^{\mathrm{c}}$ & 0.077 & 81 & $1.75(1.01-3.04)^{\mathrm{c}}$ & 0.046 \\
\hline & $p$ for interaction & & & & 0.983 & & & 0.721 \\
\hline
\end{tabular}

OR, Odds ratio; CI, confidence interval. aAdjusted for education, BMI, alcohol consumption, and betel-nut chewing. bAdjusted for education, BMI, cigarette smoking (pack-years), and betel-nut chewing. ${ }^{\mathrm{c}}$ Adjusted for education, BMI, alcohol consumption, and cigarette smoking (pack-years).

and lifestyle factors may modify the effects of these biomarkers on the risk of PMODs.

As a byproduct of oxidative DNA damage, $8-\mathrm{OHdG}$ is considered a reliable biomarker of oxidative damage (18). Research evidence has established a correlation between 8-OHdG level and PMODs and OC (8). Conversely, our analysis revealed lower levels of $8-\mathrm{OHdG}$ in patients with PMODs than in controls, indicating that a high $8-\mathrm{OHdG}$ level conferred no risk of PMODs. In this study, we obtained measurements of plasma $8-\mathrm{OHdG}$ levels, that may reflect both oxidative DNA damage and a deficient DNA-repair system. A defect in the repair of $8-\mathrm{OHdG}$ residue may indicate that $8-\mathrm{OHdG}$ levels are elevated in tissue and peripheral leukocytes, but low in plasma (19). Thus, our results may reflect a defective DNA-repair system in our case patients because plasma $8-\mathrm{OHdG}$ is derived from residual repaired $8-\mathrm{OHdG}$ in DNA. The $8-\mathrm{OHdG}$ levels measured in plasma were also lower in patients with colon cancer than in control patients (20). Similarly, Rossner et al. determined there was no association between plasma 8OHdG level and breast cancer (21).

ROS-induced lipid peroxidation has been shown to be mutagenic and may serve as a reliable biomarker of both cellular damage and DNA adducts (8). Therefore, we also assessed oxidative stress by examining plasma 8-ISO levels. Our data revealed that patients with high 8-ISO levels had increased susceptibility to PMODs and leukoplakia, which is consistent with the findings of other studies on patients with colon cancer, oesophageal cancer, and leukoplakia $(17,22$, 23 ). The sensitivity of cell membranes to ROS induces lipid peroxidation that can produce a variety of mutagenic carbonyl products (24) and contribute to neoplastic transformation.

We further examined the combined effects of 8-ISO and lifestyle factors on the risk of PMODs and leukoplakia. No significant effects were observed, but individuals with a high 8-ISO level who fell in the category of either smokers of $\leq 13$ PY or those who had ever consumed alcohol exhibited a significantly increased risk of both PMODs and leukoplakia. Alcohol consumption and smoking are established risk factors for PMODs (12). Interestingly, only those with high 8-ISO levels who had smoked for relatively few PY $(\leq 13)$ exhibited an increased risk of PMODs and leukoplakia. This may be because the majority of our participants (96\%) were cigarette smokers. When we stratified the results according to smoking status (never-smoked and ever-smoked), the results were significant for those who ever- smoked, but no results were generated for participants who had never smoked because of their small number. Since, we could not elucidate the effects of 8-ISO on PMODs in nonsmokers, further studies may be required. We observed that regardless of betel-nut chewing habit, 8-ISO only increased the overall risk of PMODs, which supports the conclusions of other 
Table IV. Association between 8-isoprostane (8-ISO) levels and risk of potentially malignant oral disorders, stratified according to genetic polymorphism.

\begin{tabular}{|c|c|c|c|c|c|c|c|c|}
\hline \multirow[b]{2}{*}{ Polymorphism } & \multirow[b]{2}{*}{ 8-ISO, $\mathrm{pg} / \mathrm{ml}$} & \multirow{2}{*}{$\begin{array}{l}\text { Controls } \\
(\mathrm{N}=208) \\
\text { Number }\end{array}$} & \multicolumn{3}{|c|}{ All cases $(N=208)$} & \multicolumn{3}{|c|}{ Leukoplakia (N=168) } \\
\hline & & & Number & OR $(95 \% \mathrm{CI})^{\mathrm{a}}$ & $p$-Value & Number & OR $(95 \% \mathrm{CI})^{\mathrm{a}}$ & $p$-Value \\
\hline \multicolumn{9}{|l|}{ GSTM1 } \\
\hline \multirow[t]{2}{*}{ Present } & $<666.21$ & 51 & 32 & 1.00 & & 24 & 1.00 & \\
\hline & $\geq 666.21$ & 51 & 57 & $1.72(0.88-3.36)$ & 0.115 & 47 & $1.92(0.92-3.98)$ & 0.081 \\
\hline \multirow[t]{3}{*}{ Null } & $<666.21$ & 53 & 47 & 1.00 & & 35 & 1.00 & \\
\hline & $\geq 666.21$ & 53 & 72 & $1.66(0.9-2.96)$ & 0.087 & 62 & $1.91(1.04-3.51)$ & 0.038 \\
\hline & $p$ for interaction & & & & 0.681 & & & 0.833 \\
\hline \multicolumn{9}{|l|}{ GSTT1 } \\
\hline \multirow[t]{2}{*}{ Present } & $<666.21$ & 45 & 36 & 1.00 & & 26 & 1.00 & \\
\hline & $\geq 666.21$ & 44 & 42 & $0.96(0.48-1.94)$ & 0.918 & 34 & $1.18(0.5-2.50)$ & 0.663 \\
\hline \multirow[t]{3}{*}{ Null } & $<666.21$ & 59 & 43 & 1.00 & & 33 & 1.00 & \\
\hline & $\geq 666.21$ & 60 & 87 & $2.31(1.29-4.13)$ & 0.005 & 75 & $2.63(1.42-4.87)$ & 0.002 \\
\hline & $p$ for interaction & & & & 0.178 & & & 0.208 \\
\hline \multicolumn{9}{|l|}{ GSTP1 } \\
\hline \multirow[t]{2}{*}{ AA } & $<666.21$ & 71 & 52 & 1.00 & & 39 & 1.00 & \\
\hline & $\geq 666.21$ & 67 & 88 & $1.82(1.07-3.10)$ & 0.027 & 72 & $2.02(1.15-3.56)$ & 0.015 \\
\hline \multirow[t]{3}{*}{$\mathrm{AG} / \mathrm{GG}$} & $<666.21$ & 33 & 27 & 1.00 & & 20 & 1.00 & \\
\hline & $\geq 666.21$ & 37 & 41 & $1.53(0.67-3.48)$ & 0.310 & 37 & $1.61(0.67-3.89)$ & 0.290 \\
\hline & $p$ for interaction & & & & 0.315 & & & 0.394 \\
\hline \multicolumn{9}{|l|}{$C Y P 1 A 1 * 2 C$} \\
\hline \multirow[t]{2}{*}{$\mathrm{AA}$} & $<666.21$ & 55 & 49 & 1.00 & & 39 & 1.00 & \\
\hline & $\geq 666.21$ & 70 & 87 & $1.69(0.97-2.93)$ & 0.064 & 77 & $1.87(1.05-3.34)$ & 0.034 \\
\hline \multirow[t]{3}{*}{$\mathrm{AG} / \mathrm{GG}$} & $<666.21$ & 49 & 30 & 1.00 & & 20 & 1.00 & \\
\hline & $\geq 666.21$ & 34 & 42 & $1.66(0.81-3.39)$ & 0.165 & 32 & $1.83(0.84-3.99)$ & 0.131 \\
\hline & $p$ for interaction & & & & 0.415 & & & 0.402 \\
\hline
\end{tabular}

8-OHdG, 8-Hydroxy-2'-deoxyguanosine; OR, odds ratio; CI, confidence interval; GSTM1, glutathione S-transferase mu 1; GSTT1, glutathione Stransferase theta $1 ;$ GSTP1, glutathione S-transferase pi $1 ; C Y P 1 A 1 * 2 C$, cytochrome $P-4501 A 1 * 2 \mathrm{C}$. aAdjusted for education, BMI, alcohol consumption, cigarette smoking (pack-years), and betel-nut chewing.

reports regarding the independent effects of both 8-ISO and betel-nut chewing on leukoplakia $(12,17)$.

Our data also demonstrated that polymorphisms of drugmetabolizing genes may modify the effects of 8-ISO on PMOD risk. Participants with high 8-ISO levels and GSTT1-null or GSTP1 AA genotypes exhibited increased risk of both PMODs and leukoplakia, whereas GSTMI-null and $C Y P 1 A 1 * 2 C$ AA genotypes exhibited an increased susceptibility to leukoplakia. These findings support those of other studies that both GST and CYP independently affect the development of PMODs and leukoplakia $(25,26)$. The adverse effects of ROS through lipid peroxidation have previously been linked to OC and leukoplakia development $(17,26)$. The development of PMODs involves multiple processes, including molecular and cellular processes, which lead to tumor formation. These processes are mediated by ROS (27), which have been determined to initiate and promote tumor formation (8). In the presence of low antioxidant levels, ROS also attack the polyunsaturated fatty acids of fattyacid membranes, causing lipid peroxidation that eventually results in changes to cell-membrane structure and functionality. The polymorphisms of GSTM1, GSTT1, GSTP1, and
$C Y P 1 A 1 * 2 C$ have been discovered to affect OC and PMODs (25). Various studies have also demonstrated the association of both GSTM1-null and CYPIAI*2C AA genotypes with increased risk of leukoplakia $(11,28)$.

Our study findings must be interpreted in light of several limitations. Firstly, we measured plasma $8-\mathrm{OHdG}$, which may reflect not only oxidative DNA stress, but also DNA repair efficiency. SecondIy, we did not include nutritional and psychological factors, which may have some effects on oral tumors. Thus, the exclusion of these confounding factors in future studies may be required in order to determine the effects of oxidative stress on PMODs. Finally, our participants were males from a penitentiary and therefore might not be representative of the general Taiwanese population.

\section{Conclusion}

Our findings revealed that an elevated level of plasma 8-ISO, but not $8-\mathrm{OHdG}$ in patients with PMOD compared to control patients might indicate the prominence of lipid peroxidation in the development of PMODs, particularly leukoplakia. 


\section{Acknowledgements}

The Authors are grateful to study participants.

\section{References}

1 Su C-C, Tsai K-Y, Hsu Y-Y, Lin Y-Y and Lian I-B: Chronic exposure to heavy metals and risk of oral cancer in Taiwanese males. Oral Oncol 46(8): 586-590, 2010.

2 Swenberg JA, Lu K, Moeller BC, Gao L, Upton PB, Nakamura $\mathrm{J}$ and Starr TB: Endogenous versus exogenous DNA adducts: Their role in carcinogenesis, epidemiology, and risk assessment. Toxicol Sci 120(Suppl 1): S130-S145, 2011.

3 Valko M, Rhodes CJ, Moncol J, Izakovic M and Mazur M: Free radicals, metals and antioxidants in oxidative stress-induced cancer. Chem Biol Interact 160(1): 1-40, 2006.

4 Marczynski B, Rozynek P, Kraus T, Schlosser S, Raithel HJ and Baur X: Levels of 8-hydroxy-2'-deoxyguanosine in DNA of white blood cells from workers highly exposed to asbestos in Germany. Mutat Res 468(2): 195-202, 2000.

5 Xing F, Li Z, Sun A and Xing D: Reactive oxygen species promote chloroplast dysfunction and salicylic acid accumulation in fumonisin B1-induced cell death. FEBS Lett 587(14): 2164$2172,2013$.

6 Thomson CA, Giuliano AR, Shaw JW, Rock CL, Ritenbaugh CK, Hakim IA, Hollenbach KA, Alberts DS and Pierce JP: Diet and biomarkers of oxidative damage in women previously treated for breast cancer. Nutr Cancer 51(2): 146-154, 2005.

7 Ma N, Tagawa T, Hiraku Y, Murata M, Ding X and Kawanishi S: 8-Nitroguanine formation in oral leukoplakia, a premalignant lesion. Nitric Oxide 14(2): 137-143, 2006.

8 Choudhari SK, Chaudhary M, Gadbail AR, Sharma A and Tekade S: Oxidative and antioxidative mechanisms in oral cancer and precancer: A review. Oral Oncol 50(1): 10-18, 2014.

9 Sheweita SA: Drug-metabolizing enzymes: Mechanisms and functions. Curr Drug Metab 1(2): 107-132, 2000.

10 Sosa V, Moliné T, Somoza R, Paciucci R, Kondoh H and Lleonart ME: Oxidative stress and cancer: An overview. Ageing Res Rev 12(1): 376-390, 2013.

11 Li YF, Sung FC, Tsai MH, Hua CH, Liu CS, Huang YT and Yeh $\mathrm{CC}$ : Interactions between cigarette smoking and polymorphisms of xenobiotic-metabolizing genes: The risk of oral leukoplakia. Dis Markers 34(4): 247-255, 2013.

12 Kadashetti V, Shivakumar KM, Chaudhary M, Patil S, Gawande $\mathrm{M}$ and Hande A: Influence of risk factors on patients suffering from potentially malignant disorders and oral cancer: A casecontrol study. J Oral Maxillofac Pathol 21(3): 455-456, 2017.

13 Warnakulasuriya $\mathrm{S}$, Johnson $\mathrm{NW}$ and van der Waal I: Nomenclature and classification of potentially malignant disorders of the oral mucosa. J Oral Pathol Med 36(10): 575-580, 2007.

14 Speight PM, Khurram SA and Kujan O: Oral potentially malignant disorders: Risk of progression to malignancy. Oral Surg Oral Med Oral Pathol Oral Radiol 125(6): 612-627, 2017.

15 Chiang C-J, Lo W-C, Yang Y-W, You S-L, Chen C-J and Lai M$\mathrm{S}$ : Incidence and survival of adult cancer patients in Taiwan, 2002-2012. J Formos Med Assoc 115(12): 1076-1088, 2016.

16 Poulsen HE, Prieme H and Loft S: Role of oxidative DNA damage in cancer initiation and promotion. Eur $\mathrm{J}$ Cancer Prev 7(1): 9-16, 1998.
17 Srivastava KC and Shrivastava D: Analysis of plasma lipid peroxidation and antioxidant enzymes status in patients of oral leukoplakia: A case-control study. J Int Soc Prev Community Dent 6(Suppl 3): S213-s218, 2016.

18 Ziech D, Franco R, Georgakilas AG, Georgakila S, MalamouMitsi V, Schoneveld O, Pappa A and Panayiotidis MI: The role of reactive oxygen species and oxidative stress in environmental carcinogenesis and biomarker development. Chem Biol Interact 188(2): 334-339, 2010.

19 Kondo S, Toyokuni S, Tanaka T, Hiai H, Onodera H, Kasai H and Imamura M: Overexpression of the hOGG1 gene and high 8-hydroxy-2'-deoxyguanosine (8-OHdG) lyase activity in human colorectal carcinoma: Regulation mechanism of the $8-\mathrm{OHdG}$ level in DNA. Clin Cancer Res 6(4): 1394-1400, 2000.

20 Niedernhofer LJ, Daniels JS, Rouzer CA, Greene RE and Marnett LJ: Malondialdehyde, a product of lipid peroxidation, is mutagenic in human cells. J Biol Chem 278(33): 3142631433, 2003.

21 Rossner P Jr., Gammon MD, Terry MB, Agrawal M, Zhang FF, Teitelbaum SL, Eng SM, Gaudet MM, Neugut AI and Santella RM: Relationship between urinary 15-F2t-isoprostane and 8oxodeoxyguanosine levels and breast cancer risk. Cancer Epidemiol Biomarkers Prev 15(4): 639-644, 2006.

22 Brys M, Morel A, Forma E, Krzeslak A, Wilkosz J, Rozanski W and Olas B: Relationship of urinary isoprostanes to prostate cancer occurrence. Mol Cell Biochem 372(1-2): 149-153, 2013.

23 Freitas Bde J, Lloret GR, Visacri MB, Tuan BT, Amaral LS, Baldini D, de Sousa VM, de Castro LL, Aguiar JR, Pincinato Ede C, Mazzola PG and Moriel P: High 15-F2t-isoprostane levels in patients with a previous history of nonmelanoma skin cancer: The effects of supplementary antioxidant therapy. Biomed Res Int 2015: 963569, 2015.

24 Benamira M, Johnson K, Chaudhary A, Bruner K, Tibbetts C and Marnett LJ: Induction of mutations by replication of malondialdehyde modified M13 DNA in Escherichia coli: Determination of the extent of DNA modification, genetic requirements for mutagenesis, and types of mutations induced. Carcinogenesis 16(1): 93-99, 1995.

25 Liu H, Jia J, Mao X and Lin Z: Association of CYP1A1 and GSTM1 polymorphisms with oral cancer susceptibility: A metaanalysis. Medicine 94(27): e895, 2015.

26 Chole RH, Patil RN, Basak A, Palandurkar K and Bhowate R: Estimation of serum malondialdehyde in oral cancer and precancer and its association with healthy individuals, gender, alcohol, and tobacco abuse. J Cancer Res Ther 6(4): 487-491, 2010.

27 Valko M, Jomova K, Rhodes CJ, Kuca K and Musilek K: Redox- and non-redox-metal-induced formation of free radicals and their role in human disease. Arch Toxicol 90(1): 1-37, 2016.

$28 \mathrm{He} \mathrm{P}$, Wei M, Wang Y and Liu Q: Associations among glutathione S-transferase T1, M1, and P1 polymorphisms and the risk of oral leukoplakia. Genet Test Mol Biomarkers 20(6): 312$321,2016$. 